\title{
Nalbuphine (Nubain): non-prescribed use, injecting, and risk behaviors for blood- borne viruses
}

\author{
BY KAREN MCELRATH AND DOMINIC CONNOLLY
}

Nalbuphine hydrochloride is a synthetic opiate with agonist-antagonist properties that has been prescribed for pain relief in several countries in North and Central America, Europe, and elsewhere. Marketed for several years under the tradename Nubain(B, the drug was believed to have low potential for dependence. Research into nalbuphine misuse is limited but studies have documented misuse among some bodybuilders, weightlifters, and users of anabolic steroids. This study examines patterns of nalbuphine misuse and injecting behaviors that pose risk for blood-borne viruses among ten respondents residing largely in one community in Ireland. Contrary to other research findings, most individuals had no history of weightlifting and no experience with the use of anabolic steroids. Most of the respondents had injected nalbuphine several times per day, and reported frequent injection of stimulants. Tampered bottle caps had been observed by respondents who also reported that needles and syringes were scarce. At least some of the nalbuphine in the region has been found to be "counterfeit." Implications of the findings are discussed.

AUTHORS' NOTE: This study was funded by the Sperrin Lakeland Health and Social Services Trust (Northern Ireland). Points of view are those of the authors. The authors are grateful to earlier comments from Andrew McBride, Lee Monaghan, and Harrison G. Pope. 
For approximately 25 years, nalbuphine hydrochloride (Nubain ${ }^{\circledR}$ ), a synthetic opiate with agonist-antagonist properties, was prescribed for pain relief in several countries in North and Central America, Europe, and elsewhere. The drug was distributed in parenteral solutions only, so that injection was the primary method of administration. In December 2004, Bristol-Myers Squibb, the manufacturer of Nubain ${ }^{\circledR}$, discontinued worldwide production of the drug. Company staff in a United Kingdom (UK) office later reported that low profits generated from Nubain $B$ prescriptions contributed to the decision to discontinue production-at least in Europe (communication with BristolMyers UK office, October 19, 2005). Bristol-Myers Squibb still holds the license for Nubain ${ }^{\circledR}$, however, other pharmaceutical companies may distribute nalbuphine, if licensed under different names.

Early reports concluded that there were "no known cases of street abuse" involving nalbuphine (Peachey 1987:352), and the drug was believed to produce low levels of dependency (Jasinski \& Mansky 1972; Schmidt et al. 1985).' However, the number of prescriptions for nalbuphine increased during the 1990s in some countries, leading some scholars to suggest that the drug had greater "addictive potential" than previously assumed (Camacho et al. 2001:469; Wines et al. 1999:161). Very few studies have focused on nalbuphine misuse, and research that has addressed the issue has focused primarily on individuals with a history of body building, weightlifting, or anabolic steroid use. ${ }^{2}$

Three studies have documented nalbuphine misuse among bodybuilders or anabolic steroid users in England or Wales (McBride et al. 1996; Monaghan et al. 2000; Williams et al. 2000). Combined, the data from the studies were collected from a total of 17 respondents or clients. Years of use (range 1 to 8 years) was reported by Williams et al. (2000) and peak daily dosage reached or exceeded $100 \mathrm{mg}$ for some respondents in all three studies. Intravenous use often 
followed subcutaneous or intramuscular injection, and frequent daily injections were common. Although the authors of one study reported that a few respondents had "shared" injecting equipment (Williams et al. 2000:20), data regarding injecting behaviors generally were not described in the studies. Clients initiated nalbuphine injections primarily to treat pain associated with injury or weightlifting (McBride et al. 1996; Williams et al. 2000). However, Monaghan et al. (2000:section 5.8) found that persons who had injected nalbuphine did not describe the drug as a "useful training aid," and most interviewees in that study condemned the use of nalbuphine, likening the drug to heroin and assigning "junkie" status to users of the drug.

Misuse of nalbuphine also has been reported among anabolic steroid users in the United States. Wines et al. (1999) interviewed 11 respondents who were users of anabolic steroids and nalbuphine. Respondents were recruited from other research projects that addressed the use of anabolic steroids, a drug treatment inpatient unit, and a psychiatric outpatient setting. Respondents' ages ranged from 19 to 42 years, and five of the 11 respondents were female. Similar to research conducted in the UK described above, daily dosage of nalbuphine often exceeded $100 \mathrm{mg}$ per day. Eight of the 11 respondents reported that nalbuphine was the first drug that they had used intravenously. In a separate study of 227 males in treatment for opiate dependency, 21 reported a history of anabolic-androgenic steroid use. The majority of this group reported that they had used opiates to reduce the negative effects, e.g., insomnia, depression, irritability, of their steroid use (Arvary \& Pope 2000).

Taken together, this body of research suggests that nalbuphine misuse has been associated largely with bodybuilders or weightlifters, although misuse of the drug does not appear to be widespread within these groups. Some but not all of the individuals who participated in these studies also had used anabolic steroids. 
In the mid- to late 1990s, anecdotal and media reports as well as observations by health professionals suggested the possibility of a pattern of nalbuphine misuse in Derry, a city located in Northern Ireland. ${ }^{3}$ Prior to this time, drug treatment professionals in the region had not come across the use of nalbuphine among clients presenting for treatment. Because clients presenting for treatment were injecting the drug, treatment professionals also were concerned about the transmission of blood-borne viruses through injecting practices. In Northern Ireland, public health and epidemiological data on nalbuphine use and misuse are not collected. A Northern Ireland general population survey of 3,516 persons aged 15-64 found that self-reported lifetime use of nalbuphine was slightly higher in the Western health board that includes the city of Derry (.2\% overall; $.4 \%$ among males and younger persons), compared to the three other health board areas (overall 0-.1\%) (MORI MRC, n.d.). A total of 591 individuals residing in the Western board participated in the survey, therefore these figures are small, i.e., representing fewer than three respondents. Additionally, surveys may underestimate drug use/misuse. Arrest and seizure data involving nalbuphine have limited relevance because nalbuphine is not controlled under the (United Kingdom) Misuse of Drugs Act (the drug is also nonscheduled in the United States). Thus, possessing the drug for personal use is not a criminal offense, although the supply of nalbuphine without medical authorization does violate the Misuse of Drugs Act. As of November 2004, police in the Derry area recalled only one criminal conviction involving nalbuphine (communication with the Police Service of Northern Ireland, Drug Liaison Unit, Derry; November 12, 2004).

The purpose of the present study was twofold. First, we explored patterns of nalbuphine use among a small sample of respondents residing largely in Derry, Northern Ireland. Second, we examined risk behaviors for blood-borne viruses, in relation to nalbuphine injection. 


\section{Methods}

Study announcements were distributed through a number of venues, e.g., two pharmacy-based needle exchange schemes, local community schemes, drug services, health centers, and the offices of selected general practitioners in the Derry area. The first author visited two gyms in the Derry area that were known to be frequented by bodybuilders. However, staff there would not permit copies of the study announcement to be placed on notice boards, claiming that nalbuphine was not used in the gyms. In addition to distributing study announcements through various venues, respondents who completed an interview were asked to refer other potentially suitable respondents to the study.

The interview guide concentrated primarily on first and last use of nalbuphine, patterns of drug taking, risk behaviors associated with injecting and experiences with drug treatment. Face-to-face interviews were used to collect the data. Interviews were conducted during 2003-2004 in private residences, semi-public areas, or other settings that were convenient to the respondent. Interviews were not taped; rather the first author took very detailed notes while she conducted the interviews. This decision was influenced primarily by the local social and political context in relation to drug use. The use of drugs (other than alcohol) and injection in particular are highly stigmatized behaviors in the communities where potential respondents were thought to be residing. The various informal social control mechanisms that are in place (McElrath 2004) deter individuals from revealing aspects of their identities associated with illicit drug use. Taped interview data produces voice identification so that at times tapes are viewed suspiciously.

Ethical approval was obtained from the Queen's University Medical Ethics Committee. Respondents were assured confidentiality and anonymity and paid $£ 20$ for a completed interview. The detailed interview notes were reviewed several 
times within 48 hours of each interview, and then typed by the first author. Themes emerged which were explored further as the interviews progressed, and coding schemes were developed.

\section{Findings ${ }^{4}$}

Ten persons were recruited for an interview. Respondents' ages ranged from 21 to 50 years. Most respondents were male although many reported knowing females who had used nalbuphine. A female injector who was interviewed in a larger study of injecting drug use (McElrath \& Jordan 2005) reported knowing other females who initiated injection through nalbuphine, although they subsequently preferred to inject heroin.

At the time of the interview, three respondents were in fulltime employment and four respondents owned their homes. None were homeless. The majority $(\mathrm{N}=7)$ lived with a partner, and only one respondent reported that the partner also used nalbuphine regularly. Two respondents reported a relatively "active" nightlife consisting of frequent visits to local clubs.

Seven of the ten respondents resided in the Derry area at the time of the interview. Three others resided in or near Ballymena, a town located approximately 50 miles from Derry, and characterized by a disproportionate number of heroin users. Contrary to previous research into the misuse of nalbuphine, only two respondents in the present study had a history of bodybuilding or weightlifting.

Patterns of The age at which nalbuphine was first used ranged from 18 to nalbuphine 34 years, and none of the respondents had been prescribed use nalbuphine for pain relief. Four persons were injected first by a bodybuilder. One respondent, a former bodybuilder, was injected first by a female who worked in a health profession. 
Nine of ten respondents reported that they had not "planned" to inject nalbuphine; rather, they were in the presence of another individual who had injected it before and the drug was available in this setting. Four respondents reported that nalbuphine was the first drug that they had injected.

One respondent was 22 years of age when he first injected nalbuphine. He had never used opiates prior to using nalbuphine and he recalled that his drug use was confined largely to alcohol and cannabis:

"I was selling drugs [cannabis] at the time. A friend-well, a socalled friend said, 'Try some of this [nalbuphine].' I was drunk and tried it then and that was me, hooked."

I: "How did it make you feel?"

R: "Sick-I was so sick for the first few times, but it was a good feeling."

The male acquaintance showed him how to inject into a vein. The respondent was self-injecting by the second injection episode which occurred approximately two weeks later. A respondent and former bodybuilder recalled his first injection of nalbuphine, which occurred in the late 1980s in the Ballymena area, about five years after he had first injected anabolic steroids:

"I was with a mate then, from XXX [small village located near Ballymena]. He gave me a $10 \mathrm{ml}$ bottle of Nubain $®$, said, 'Put that into your vein.' I used it in a muscle first and used $1 \mathrm{ml}$ at a time. The second time I used it, I injected into a vein. Used an insulin needle then. Real addictive stuff."

This respondent recalled a network of approximately 30 bodybuilders who used nalbuphine during the 1980s-1990s and resided in Derry, Ballymena, and areas located near these regions.

Four of ten respondents reported current use of nalbuphine (i.e., injected during the past 30 days), and the majority $(\mathrm{N}=8)$ had injected either nalbuphine or other drug during the 
30-day period prior to the interview. Nine had injected nalbuphine intravenously and frequent users of nalbuphine most often injected into a vein located in the arms or legs:

"You might be able to inject into a muscle but I think your arm would go black."

Two respondents had injected nalbuphine into the groin area, although only one had injected nalbuphine into the neck.

One respondent injected nalbuphine each day for a period of four to five years and two others injected the substance for approximately eight years. A $10 \mathrm{ml}$ bottle of nalbuphine can be used for at least 10 injections when using a $1 \mathrm{ml}$ syringe. These three respondents reported peak usage at $10 \mathrm{mls}$ per day, injecting every few hours, and a fourth had injected approximately $12 \mathrm{mls}$ per day at peak usage. Seven of ten respondents recalled lengthy periods of time in which they had injected nalbuphine daily.

A former bodybuilder reported peak usage of three times per day with $3 \mathrm{mls}$ used during each injection episode. He first injected into a muscle, ${ }^{5}$ however, after injecting into a vein for the first time:

"I never used it again in a muscle. There's not really a buzz when you inject Nubain ${ }^{\circledR}$ into a muscle. But into a vein - a big difference. Once you want one you want another. I found myself waking up in the morning and injecting it. Never was like that before. I got so I didn't want to go out, would have a hit just to feel good, had nothing to do with recovering from a workout. I used it for six months and it started to affect my lifestyle. I even started not going to the gym. I just had to stop using."

One respondent had used nalbuphine for several years, and reported a peak usage of approximately $20 \mathrm{mls}$ per week. The respondent injected .2 to $.4 \mathrm{mls}$ during each injection. Although the weekly dose was comparatively low, he reported an average of 75 injections per week at peak usage. A similar pattern of frequent injecting was observed in 
research conducted with bodybuilders (i.e., Williams et al. 2000).

Use of Nine of ten respondents reported that cannabis was the first nalbuphine "illicit" drug that they had used. Only one person (a female) and other had used cannabis and nalbuphine only; other respondents drugs reported a history of occasional or frequent use of 3.4Methylenedioxymethaphetamine (MDMA) and amphetamine that preceded nalbuphine injection.

Six respondents had used heroin. Of this group, four had injected heroin, and two had smoked heroin on one occasion only, but had never injected it. Thus, four individuals had injected both nalbuphine and heroin. Of this group, two respondents had injected nalbuphine prior to injecting heroin whereas two others had injected heroin prior to injecting nalbuphine. Two of the ten respondents had used nalbuphine on one occasion only when their drug of choice (i.e., heroin) was not accessible. Both had been injecting heroin for at least two years prior to using nalbuphine, and neither resided in the Derry area. One of these respondents reported:

R: "You can get it on the Internet. I was off the gear [heroin] for 2 or 3 days. They say you have to be off the gear for a few days before you start taking it [nalbuphine]. Not as strong as gear would be. [Small village in County Antrim] - seems to be about there. I didn't like it that much. Rushes, a downer. It just wasn't the feeling I liked. First rush I got off Nubain $®$ was something like MSTs [Morphine Sulphate Tablets]."

The respondent reported that he had been given nalbuphine by a male acquaintance who was a bodybuilder:

I: "Did you inject into a muscle or a vein?"

R: "I think it was a muscle. I think he injected me in the bum."

I: "Can you get a habit from Nubain®?"

R: "I think they must have had a habit, because they were taking the gear [heroin] and then they went off that. then on the Nubain $\otimes$. Must have been habits." 
I: "Would it stop the sickness? Stop the rattling [withdrawal], if you were using the gear?"

R: "Well it sorted me out for a few days." 6

Although six respondents in the present study had used heroin and four had injected it, most respondents belonged exclusively to social networks that were not overtly connected to networks of heroin users.

Five respondents who reported regular use of nalbuphine tended to also report frequent use of stimulant drugs, although not necessarily during the same time periods. For example, one respondent began to inject cocaine after initiating injecting with nalbuphine. He estimated that his peak use of cocaine was 3 to 4 grams administered through 10 to 15 injections per day. This pattern continued for a number of years until a personal crisis prompted him to cease using cocaine. At the time of the interview he had not used cocaine in five months and recovery was largely due to selfhelp. However, he still was injecting nalbuphine on a daily basis. Another respondent initiated injection with anabolic steroids, injected nalbuphine intravenously for a period of approximately six months and then proceeded to smoke and inject crack cocaine for seven years. He had smoked heroin for a period of one year but only to ease the "come down" associated with crack cocaine. Two other respondents injected nalbuphine for a period of several months, but preferred to inject amphetamine. In their U.S.-based study of weightlifters who injected nalbuphine, Wines et al. (1999) observed that 5 of 11 respondents had a history of dependence on cocaine or other stimulant drug.

Price and the possibility of a counterfeit drug market
The interview data revealed that the price of nalbuphine varied widely over time and context. Some respondents in the Derry area recalled that a $10 \mathrm{ml}$ bottle of nalbuphine at one time sold for $£ 25$. Several vials are sometimes sold in one package with the vials wrapped in cellophane. One respondent reported that the appearance of the packaging 
resembled "stink bombs." Another respondent reported that he had recently paid $£ 40$ for a box of 10 vials of nalbuphine. Each vial contained $2 \mathrm{ml}$ of nalbuphine, and there were $20 \mathrm{ml}$ of nalbuphine in the entire box, a cost of $£ 2$ per $1 \mathrm{ml}$ of nalbuphine. Similar to other drugs purchased on the illicit market, nalbuphine appears to cost less when purchased in bulk by a regular supplier. One respondent reported that nalbuphine was available for purchase through on-line "pharmacies," although none of the respondents reported obtaining the drug through these sources.

In early 2004, the first author of the present study was conducting an interview during which the respondent showed the author a box containing several vials of liquid that the respondent had purchased a few days before the interview. The box contained 10 vials and the printed information on the box and the vials stated that the substance was Nubain ${ }^{\circledR}$. Information on the box stated that the product was manufactured by DuPont, however, DuPont ceased production of all pharmaceuticals approximately three years earlier. Given the drug's reputed shelf-life of three years, it is possible that the vials observed did contain Nubain ${ }^{\circledR}$ and were indeed manufactured by DuPont pharmaceuticals. It is also possible that the observed vials contained counterfeit Nubain ${ }^{\circledR}$, or some other substance. In 2002 , the police in Northern Ireland confiscated a "large quantity" of Nubain ${ }^{\circledR}$, determined to be counterfeit because the batch number did not match with data reported by Bristol-Myers Squibb. The box of vials observed by the first author contained instructions that appeared to be written in Arabic. Other respondents had never observed instructions printed in Arabic, however, respondents reported that the instructions as well as the box were often destroyed by persons who supplied them the drug. On a separate occasion, the second author of this article observed a vial of liquid, allegedly containing nalbuphine. However, the name Nubain ${ }^{\circledR}$ was spelled incorrectly. Taken together, these observations suggest the 
possibility that counterfeit Nubain ${ }^{\circledR}$ was sold in the Derry area. Unfortunately, we have no way of knowing whether counterfeit Nubain ${ }^{\circledR}$ contained nalbuphine at all.

Risk behaviors for bloodborne viruses
Injecting behaviors that pose risk for infectious disease, e.g., HIV and Hepatitis $C$ virus, appear to differ somewhat when injecting nalbuphine in comparison to heroin. For example, injecting heroin often involves the loaning or borrowing of needles/syringes, filters, spoons and water, and these behaviors have been linked with Hepatitis $\mathrm{C}$ among Injecting Drug Users (IDUs) (Hagan et al. 2001; Thorpe et al. 2002). Nalbuphine is typically available in liquid form so that filters and spoons are not needed to prepare the substance for injection. Thus, needles, syringes, and rinse water represent the primary injecting "tools" that can serve as conduits for the transmission of blood-borne viruses among nalbuphine injectors. Risk may be escalated, however, because regular use of nalbuphine often involves several injections per day; injection frequency has been linked with Hepatitis C seroconversion among IDUs (Hahn et al. 2001; Patrick et al. 2001).

Respondents reported that nalbuphine is a clear liquid that is available in a bottle (ampules) or vial. The vial is preferred because respondents have observed tampered caps on the bottles:

"You can see the wee holes [from other needles] in the cap."

Tampered bottle caps also were believed to produce a white residue and a loss of "pressure" in the bottle. One respondent reported that a dealer would use a needle to remove some of the nalbuphine from a bottle and then substitute with $2 \mathrm{mls}$ of water. Another recalled:

"I paid $£ 50$ one Christmas for one handful of Nubain®. Some dealers would draw a bit into a syringe and sell you the syringe if you couldn't afford a bottle." 
Bottles tampered with the needles of others could pose risk for blood-borne viruses, particularly if the needle or syringe has been used previously.

Additionally:

"There are weak bottles and strong bottles. And there's counterfeit Nubain ${ }^{\circledR}$. There are posters put up by the Police Service of Northern Ireland (PSNI) [police] and they are about counterfeit Nubain®. See, real Nubain $®$ comes in a vial. Counterfeit Nubain $®$ comes in a brown bottle, and you just stick your pin [needle] through it."

Here, the type of container that held the Nubain ${ }^{\circledR}$ was the criterion used to determine whether it was counterfeit. According to this respondent, Nubain ${ }^{\circledR}$ was distributed through vials, whereas the counterfeit substances were supplied in bottles. As described earlier, police in Northern Ireland confiscated several vials of counterfeit Nubain® in 2002.

Respondents recalled the scarcity of needles/syringes prior to the implementation of pharmacy-based needle exchanges in 2001. A respondent recalled that needles/syringes were sold for $£ 1$ each from certain dealers who were selling nalbuphine. Two other respondents provided similar accounts. This source of distribution also occurred after the provision of the two pharmacy-based needle exchanges in the area. Local drug suppliers were known to obtain needles (either directly or indirectly) through the exchange schemes and either sell or distribute them freely to buyers of nalbuphine. In particular, the free distribution via secondary exchange assisted respondents who had never visited an exchange. For these respondents, visits to the exchange represented a "wild embarrassing situation":

I: "So why won't you use the needle exchange?"

R: "I can't admit to using drugs, without getting any help. It's bad enough letting them know I used to use Nubain ${ }^{\circ}$. To get your needles from the exchange, you'd have to admit to using. I never used it [exchange] once." 
The scarcity of needles led respondents to use one needle several times over a period of days:

"You'd hang onto them because they were so hard to get."

A former bodybuilder injected anabolic steroids before injecting nalbuphine. He recalled learning how to inject from a friend who worked in nursing:

R: "She injected me and a mate. She used two needles."

I: "Do you mean two separate needles? One for you and one for your mate?"

R: "Yeah, but she used two separate needles for each of us. Once you draw the steroid up, you replace the needle. See, that first needle you use to break the cap. She said it damages a bit, and if you used it again there would be a risk for infection. So she taught us to replace the needle and use a new one for injecting the steroid."

Six respondents had engaged with drug treatment services, and five were in treatment at the time of the interview. One of these individuals, however, had used nalbuphine on one occasion only and had been prescribed high-dose buprenorphine (Subutex ${ }^{\circledR}$ ) for heroin dependence. Two others were prescribed high-dose buprenorphine and reported that they had since Treatment abstained from using nalbuphine and heroin. Both were injecting amphetamine but reported that their frequency of injecting had declined from several times to once a day since commencing the program of substitute prescribing. One respondent who had never engaged with drug treatment services had been prescribed diazepam by his doctor and he attributed his abstinence to this medication and the support of a family member. One other respondent had never participated in drug treatment but was actively involved with a local self-help group.

\section{Discussion}

Empirical research into nalbuphine misuse is limited and studies that have focused on the issue have drawn primarily from samples of bodybuilders or weightlifters. In the present 
study, eight of ten respondents had never participated in bodybuilding or weightlifting, nor had they used anabolic steroids. A few case studies and reports have highlighted nalbuphine misuse among individuals with no reported history of bodybuilding or weightlifting (e.g., Camacho et al. 2001, United States Food and Drug Administration, n.d.). However, to our knowledge this study is the first to describe patterns of nalbuphine misuse among individuals - of whom most had no prior experience with bodybuilding or weightlifting.

Our data cannot inform us about the extent of nalbuphine misuse in the Derry area. Research from other countries, e.g., the United States, has identified upward trends of the misuse of opiates that are generally available from prescription only (McCabe et al. 2005; Volkow 2005). In particular, U.S. data have shown increases in the misuse of other opioid analgesics that are intended to relieve pain (Drug Abuse Warning Network 2004; Gilson et al. 2004). It is unclear whether similar patterns will follow in Ireland. We also are unable to explain why nalbuphine misuse surfaced in Derry but does not appear to have surfaced in other parts of Northern Ireland, including its largest city, Belfast (e.g., MORI MRC, n.d.). Considerably more research is needed into drug preferences and how local contexts might shape these preferences.

From the limited number of interviews with nalbuphine users, there appeared to be no clear pattern regarding the sequence of the drugs that respondents had injected. For example, using nalbuphine did not necessarily contribute to the likelihood of injecting heroin. The data do suggest, however, that several of the nalbuphine users interviewed for this study became frequent users of cocaine or other stimulants. This pattern of polydrug use has also been observed in studies of nalbuphine use in the Boston area (Wines et al. 1999) and in Brighton (England) (Williams et al. 2000). In the latter study, the authors suggested that cocaine use was associated primarily with the occupational lifestyles of many of the clients, who 
tended to be employed in nightclubs where accessibility and opportunity to use cocaine may be enhanced. In the present study, some of the stimulant users were loosely connected with social networks of other drug users which may have provided opportunity to access other drug markets. However, one respondent with a lengthy history of cocaine use had few connections with users of other drugs and attempted to distance himself from these networks.

The data suggest that the use of nalbuphine can contribute to risk behaviors for blood-borne viruses. First, users reported injecting the drug several times per day. The frequency of injection can increase exposure to blood-borne viruses particularly among persons who inject with others. Second, respondents reported that nalbuphine was available in both vials and bottles, and some had observed bottle caps in which a needle had previously been inserted. These observations suggest that other users or suppliers had inserted needles into the cap, probably to draw nalbuphine from the bottle for their own personal use or to increase profit. The risks associated with "sharing" common ampules containing other drugs have been highlighted in studies conducted in India (Sarkar et al. 2003) and in New York City (Lankenau \& Clatts 2002). Third, respondents reported difficulties in accessing new needles/syringes, particularly before the two pharmacy-based exchanges were implemented. Moreover, some respondents sought to conceal their drug use and in doing so, avoided the exchanges entirely. As a result, respondents sought injecting equipment through secondary exchange or through drug suppliers.

We have no way of knowing the extent to which people have sourced counterfeit Nubain ${ }^{\circledR}$, although we know that counterfeit supplies have been identified in Northern Ireland. Similarly, we do not know the extent to which prescribed Nubain ${ }^{\circledR}$ has been diverted to illicit drug markets in Northern Ireland. It is possible and perhaps likely that some diversion has occurred. Given the pharmaceutical company's decision to cease production of Nubain ${ }^{\circledR}$ we are concerned about the potential 
impact on individuals who are dependent on the drug and have sourced nalbuphine largely through diverted markets. Will they now access counterfeit Nubain ${ }^{\circledR}$, will they abstain, or will they substitute with other opiate drugs? They have administered the drug via intravenous injection and may continue administering other drugs in this way. Clearly, we need to monitor the situation through additional research and discussions with clients entering treatment.

One limitation of this study concerns its small sample size $(\mathrm{N}=10)$; larger samples might yield more diverse data with regard to patterns of use and injecting behaviors. Clearly more research with larger samples of persons who inject nalbuphine is needed. Second, these cross-sectional data impede our ability to ascertain how changes in the marketing of Nubain ${ }^{\circledR}$ might have affected persons who use the drug.

Notes 1. Note, however, that Schmidt et al. were employed by DuPont Pharmaceuticals, which marketed nalbuphine under the trade name Nubain until 2001.

2. One report contained a brief mention of nalbuphine misuse among methamphetamine users in Korea. The authors indicated that some individuals consumed nalbuphine when methamphetamine became less available in the region (Yoo et al. 1995). Regarding the misuse of nalbuphine, no other details were provided by the authors.

3. In 2001, the population of the Derry City Council area was estimated to be approximately 105,000 .

4. Respondent ID numbers that normally accompany quoted material from interviewees, are omitted from this article in order to maintain anonymity. Most of the respondents reside in a small city and some health professionals are aware of some treatment clients' participation in the study. We believe that if IDs or related information were attached to interview data, some local readers might be able to link particular quotes with selected respondents.

5. Blood does not enter the syringe during intramuscular injections, so that this method of administering a drug may pose less risk for the transmission of blood-borne viruses, in comparison to intravenous injections (Lankenau \& Clatts, 2002). 
6. We are uncertain about this report; nalbuphine can escalate withdrawal symptoms in persons dependent on heroin.

Arvary, D. \& Pope, H.G. (2000) Anabolic-androgenic steroids as a gateway to opioid dependence. New England Journal of Medicine 342:1532.

Bristol-Meyers Squibb (2005) Telephone communication between employee and Karen McElrath, October 19.

Camacho, A., Matthews, S.C. \& Dimsdale, J.E. (2001) "Invisible" synthetic opiates and acute psychosis (Letter). New England Journal of Medicine 345(6):469.

Drug Abuse Warning Network (2004). Narcotic analgesics, 2002 update. The DAWN Report. Rockville, MD: Substance Abuse and Mental Health Services Administration (SAMSHA).

Gilson, A.M., Ryan, K.M., Joranson, D.E. \& Dahl, J. (2004). A reassessment of trends in the medical use and abuse of opioid analgesics and implications for diversion control: 1997-2002. Journal of Pain and Symptom Management 28:176-188.

Hagan, H., Theide, H., Weiss, N.S., Hopkins, S.G., Duchin, J.S. \& Alexander, E.R. (2001) Sharing of drug preparation equipment as a risk factor for Hepatitis C. American Journal of Public Health 91 : 42-46.

Hahn, J.A., Page-Shafer, K., Lum, P.J., Ochoa, K. \& A.R. Moss (2001) Hepatitis $C$ virus infection and needle exchange use among young injection drug users in San Francisco. Hepatology 34:180-187.

Jasinski, D. R. \& Mansky, P.A. (1972) Evaluation of Nalbuphine for abuse potential. Clinical Pharmacology and Therapeutics 13:78-90.

Lankenau, S. E. \& Clatts, M.C. (2002) Ketamine injection among high risk youth: Preliminary findings from New York City. Journal of Drug Issues 32:893-905.

McBride, A.J., Williamson, K. \& Petersen, T. (1996) Three cases of Nalbuphine hydrochloride dependence associated with anabolic steroid use. British Journal of Sports Medicine 30:69-70.

McCabe, S.E., Teter, C.J., Boyd, C.J., Knight, J.R. \& Wechsler, H. (2005) Nonmedical use of prescription opioids among U. S. college students: Prevalence and correlates from a national survey. Addictive Behaviors 30:789-805.

McElrath, K. \& Jordan, M. (2005). Drug Use and Risk Behaviours among Injecting Drug Users. Belfast, Northern Ireland: Department of 
Health, Social Services and Public Safety. Available on the World Wide Web at: http://www.dhsspsni.gov.uk/publications/2005/drug _use_and_risk_behaviours.pdf.

McElrath. K. (2004). Drug use and drug markets in the context of political conflict: The case of Northern Ireland. Addiction Research and Theory 12:577-590.

Monaghan, L., Bloor, M.. Dobash, R.P. \& Dobash, R.E. (2000) Drugtaking, risk boundaries and social identity: Bodybuilders talk about Ephedrine and Nubain. Sociological Research Online 5 (2). Available on the World Wide Web at: www.socresonline .org.uk/5/2/monaghan.html (Site may require password).

MORI MRC (n.d.). Drug Use in Ireland and Northern Ireland, 2002/2003. Drug Prevalence Survey: Health Board (Ireland) \& Social Services Board (Northern Ireland) Results (Revised). Bulletin 2. Belfast, Northern Ireland: DAIRU. Department of Health, Social Services and Public Safety, Dublin. Ireland: National Advisory Committee on Drugs.

Patrick. D.M., Tyndall. M.W., Cornelisse, P.G.A., Li, K., Sherlock. C.H., Rekart, M.L., Strathdee, S.A.. Currie, S.L.. Schechter, M.T. \& O'Shaughnessy, M.V. (2001) Incidence of Hepatitis C virus infection among injection drug users during an outbreak of HIV infection. CMAJ/ 165:889-895.

Peachey, J.E. (1987) Clinical observations of agonist-antagonist analgesic dependence. Drug and Alcohol Dependence 20:347-365.

Police Service of Northern Ireland (2004) Telephone communication between member of the Drug Liaison Unit, Derry City, and Karen McEltath. November 12.

Sarkar. K.. Mitra, S.. Bal. B.. Chakraborty, S., \& Bhattacharya. S.K. (2003) Rapid spread of Hepatitis $C$ and needle exchange programme in Kolkata. India. Letter. Lancet 361 (April 12):1301-1302.

Schmidt. W.K.. Tam . S.W.. Shotzberger, G.S., Smith, D.H., Clark, R. \& Vernier, V.G. (1985) Nalbuphine. Drug and Alcohol Dependence 14:339-362.

Thorpe, L.E., Ouellet, L.J. Hershow. R., Bailey, S.L., Williams, I.T., Williamson. J.. Monterroso, E.R. \& Garfein, R.S. (2002) Risk of Hepatitis $C$ virus infection among young adult injection drug users who share injection equipment. American Journal of Epidemiology 155:645-653.

United States Food and Drug Administration (n.d.) Physician burglarizes former medical practice. Available on the World Wide Web at: www fda.gov/ora/aboutenf story/ch6/oci3 htm. 
Volkow, N.D. (2005) Confronting the rise in abuse of prescription drugs. NIDA Notes 19(5):3.

Williams, H., Remedios. A., Rooney, J. \& Hanstock, R. (2000). Nalbuphine dependence: A brief report from the UK. Irish Journal of Psychological Medicine 17:20-21.

Wines, J.D., Gruber, A.J., Pope, H.G. \& Lukas, S. (1999) Nalbuphine hydrochloride dependence in anabolic steroid abusers. American Journal of Addictions 8:161-164.

Yoo, Y-C., Chung, H-S., Kim, I-S., Jin. W-T. \& Kim, M-K. (1995) Determination of Nalbuphine in drug abusers' urine. Journal of Analytical Toxicology 19:120-123. 
Copyright of Contemporary Drug Problems is the property of Federal Legal Publications Inc. and its content may not be copied or emailed to multiple sites or posted to a listserv without the copyright holder's express written permission. However, users may print, download, or email articles for individual use. 